\title{
ESTADO DA ARTE NA AMÉRICA LATINA E NOS PAÍSES DO NORTE GEOECONÔMICO "PAISES DESENVOLVIDOS"
}

\author{
Samila Mirelly Ferreira Silva ${ }^{1}$ \\ Diógenes José Gusmão Coutinho. ${ }^{2}$
}

RESUMO: O presente artigo tem como objetivo discutir os procedimentos e limites dos estudos denominados de Estado da Arte nos países desenvolvidos ao apresentar sobre o tema correlacionando o estudo $\mathrm{da}$ arte com técnica geoeconômica pretende-se apresentar fundamentos na modalidade de pesquisas que estude os países desenvolvidos de acordo as áreas em expansão podendo contribuir com levantamento, mapeamento e analise do se produz considerando as áreas de conhecimentos de acordo com espaço, forma e condições de produção. Utilizou-se como metodologia pesquisas de estrutura bibliográfico, onde foram utilizados artigos e periódicos em meio digital. O presente artigo destaca, de forma sistemática e analítica, a relevância dos processosde avaliação, sistematizando informações sobre aspectos conceituais, e o estado da arte dos estudossobre os países desenvolvidos.

Palavras-chave: América Latina. Desenvolvimento. Estado da Arte

ABSTRACT: This article aims to discuss the procedures and limits of studies called State of the Art in developed countries by presenting on the subject correlating the study of art with geoeconomic technique. the expanding areas being able to contribute with survey, mapping and analysis of what is produced considering the areas of knowledge according to space, form and production conditions. The methodology used was bibliographic research, where articles and journals in digital media were used. This article systematically and analytically highlights the relevance of evaluation processes, systematizing information on conceptual aspects, and the state of the art of studies on developed countries.

keywords: Latin America. Development. State of the Art

\footnotetext{
${ }^{1}$ Graduado em Matemática Pela FAMASUL em ... Aluno de Especialização ... pela Faculdade Alpha. E-mail:

2 Graduado em Biologia pela UFRPE. Doutor em Biologia pela UFPE. E-mail: alphadiogenes@gmail.com
} 


\section{INTRODUÇÃO}

Em âmbito mundial educação, ciência e tecnologia constituem a base da pesquisa científica e tecnológica, em nível de ciência básica e/ou aplicada elaboradas a partir de instrumentos como na $I^{\circ}$ revolução industrial no século XVII na descoberta da mecanização, indústria da máquina á vapor e do carvão, na $2^{\circ}$ revolução industrial no século XIX, na linha de montagem, como base de petróleo e eletricidade, na $3^{\circ}$ revolução industrial no século XX na produção automatizada, utilizando computadores e TI GPS e por que não chamar a nossa $4^{\circ}$ revolução industrial relacionada a internet, levando em consideração os produtivos inovadores que contribuem e viabilizam a melhoria na vida das pessoas, além de processos produtivos em diversos campos do conhecimento humano.

Fitoussi e Rosanvallon (1996) argumentaram em favor de uma nova era da desigualdade na sociedade capitalista desenvolvida. De acordo com os autores, sua particularidade é produto daocorrência de três processos concomitantes e interdependentes: i. de enfraquecimento dos princípios de igualdade na sociedade com enfraquecimento dos interesses coletivos; ii. de naturezaestrutural relacionado às mudanças nas estruturas de renda disponível, de gasto e de patrimônio;

iii. de natureza dinâmica associada à dinâmica das instituições jurídica e econômica e tecnológica.

Segundo a pesquisa do CNPq (2010) a percepção que o brasileiro tem é que "Cientistas são pessoas inteligentes que fazem coisas úteis á humanidade e que o interesse maior é ajudar a humanidade"

No Brasil o índice de cientista é baixo, visto que muitos profissionais capacitados não trabalha em sua área.

Os países de primeiro mundo são os que apresentam taxas de desenvolvimento político econômico e social satisfatórias, pois são países em que a população estão sempre em busca de aprender, onde as pessoas expões os seus pensamentos e desejos sem que tenham um retrocesso futuro. 
A população desses países tem uma qualidade de vida elevada, pois existem vários fatoresque influencia nesta causa, como a alimentação, assistência médica, poluição, além de um nível de industrialização e desenvolvimento, os Produto Interno Bruto (PIB), renda per capita e Índice de Desenvolvimento Humano (IDH). Dentre eles encontra-se Noruega, Suíça, Suécia, Austrália Japão e Estados Unidos.

O desenvolvimento de um país é instituído pela geração de industrias e onde tenha uma predominância do setor terciário na economia, no ano de 2015, e umas análises foram feitas pelo Programa das Nações Unidas para o Desenvolvimento (PNUD) onde deixam no ranque os io países mais desenvolvidos. Um dos parâmetros muito interessante que para enquadra-se nospaíses industrializados é de ter uma elevada expectativa de vida e baixas taxas de mortalidade infantil.

Os países não apresentam aspectos uniformes, ou seja, existem diferentes mecanismos parao desenvolvimento de cada um deles, de acordo o mercado econômico, posição financeira e gestãopública. Entretanto, algumas características podem ser percebidas na maior parte deles. Entre elasestão:

Produto Interno Bruto (PIB), Renda Per Capta, países que colonizaram países menores, taxa de natalidade e mortalidade.

Os países em desenvolvimento passa por uma transição muito difícil, visto que para se caracterizar um país desenvolvido, o país precisa possuir um número elevado de pessoas com umpadrão de vida alto, ou seja precisa ser um ambiente onde a grande massa precisa possuir um padrão médio e alto com a uma industrialização adequada.

Exemplos de países em desenvolvimento é:

- Brasil

- Argentina

- Colômbi

Os fatores que contribuem para que o Brasil não seja um país desenvolvido é :a

- Pobreza e desigualdade social; 


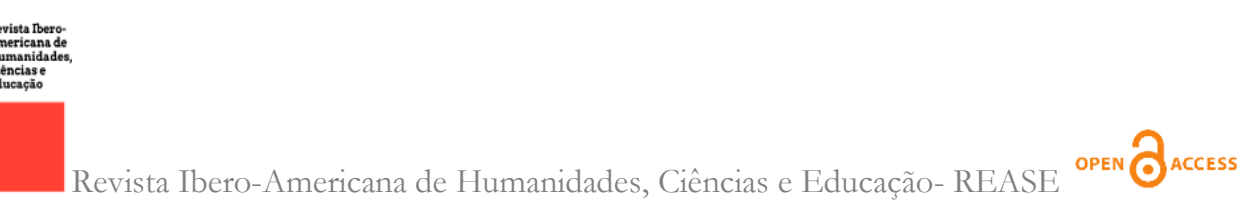

- Educação e saúde;

- Qualidade de vida;

- País de classe média;

\section{METODOLOGIA}

O método utilizado é de analise bibliográfica atrelado a pesquisa de campo de modo quantitativo e qualitativo.

De acordo com Moraes (2003), o intuito é compreender e ajudar a melhorar os fenômenosde investigação, seja tecnológico ou manual, com objetivo de ampliar e descobrir a transformar ocampo teórico que se trabalha de forma ampla.

Logo ele acredita que os cientistas buscam melhoria se auto conhecendo, para daí então, ajudar naampliação de futuros meios para a sociedade.

A análise deste presente artigo foi realizada de forma analítica, onde a partir de um roteiro de observação virtual, desenvolvida utilizando o Programa Google Acadêmico como ferramenta principal de pesquisa em artigos e periódicos em meio digital que fomente e caracterize os países de desenvolvidos, as ações que contribuem para que estejam em constantes modernizações e desenvolvimento.

O intuito desta pesquisa foi analisar alguns trabalhos científicos, com aprofundamento de mostrar onde o Brasil se encontra na sua economia, e mostrar o porquê de não ser um país desenvolvido, mesmo com toda sua riqueza.

\section{FUNDAMENTAÇÃO TEÓRICA}

Países desenvolvidos são nações com elevado desenvolvimento econômico e social. Essa classificação utiliza critérios como grau de riqueza, nível de industrialização, desenvolvimento e grau de escolaridade.

Produto Interno Bruto (PIB), renda per capita e Índice de Desenvolvimento Humano 
(IDH).

O desenvolvimento econômico é também um critério preponderante de classificação.

Os países desenvolvidos possuem alto grau de industrialização e alta renda per capita. Apresentam IDH próximo a $\mathrm{I}$, indicando boa qualidade e expectativa de vida, bem como amplas oportunidades de educação.

Segundo o professor Carlos Brito Cruz, diretor científico da Fapesp, o modelo de financiamentoapropriado para a realidade brasileira é que o país use os recursos dos impostos para "ajudar a educar os estudantes a serem criativos e imaginativos em suas carreiras". Logo, percebe-se que se investir na educação as chances de ter um país desenvolvido futuramente é maior, pois os estudantes terá liberdade de expor suas criatividades com qualidade.

Dominam economicamente outros países e apresentam desenvolvimento econômico estável. Geram receitas por meio do setor industrial. Reduzidas taxas de mortalidade, mortalidadeinfantil e natalidade.

Os países do Norte são caracterizados pelo elevado Produto Interno Bruto (PIB) e pelas condições históricas de poder e acúmulo de riquezas. São representados, em geral, pelos Estados Unidos, União Europeia e Japão. Apesar das boas condições econômicas, nesses países também existem desigualdades sociais e pessoas em condições de acentuada pobreza 1 , pequena referente aos países subdesenvolvidos.

A aceleração da inflação e a redução das taxas de crescimento, presentes na maioria dos países da região, após a crise do petróleo de 1973, levaram ao fortalecimento da posição dos críticos ao modelo de ISI, surgindo a partir de então proposições de política que alterariam radicalmente o padrão adotado a partir dos anos 1950. Os objetivos dessas recomendações não selimitavam apenas aos aspectos relacionados com a estabilização econômica, mas iam além ao formularem a proposição de uma completa transformação da estrutura produtiva, por meio da redução da intervenção do Estado na economia, liberalização e abertura comercial.

A maior parte dessas medidas integrava o receituário das agências internacionais como condição para concessão de ajuda financeira Bittencourt e Marinho (2007, apud Reinhardt e Peres,200o). 


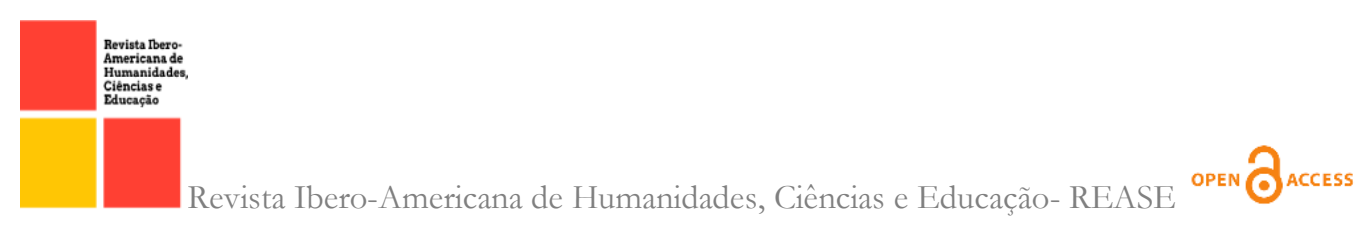

Embora há maior parte das nações desenvolvidas possuam elevado padrão de vida, nessespaíses também existem problemas sociais, como desemprego, violência, analfabetismo, fome e mortalidade infantil. O que difere esses países dos subdesenvolvidos é que a quantidade de pessoas vivendo em condições precárias é muito inferior às encontradas nos países pobres. Além disso, em geral, são asseguradas algumas necessidades básicas - como alimentação e acesso à educação, onde uns mesmo com toda inteligência e muitos esforços não conseguem ingressar na vida acadêmica - à população de baixa renda.

\section{RESULTADOS E DISCUSSÃO}

Toda pesquisa foi em caráter bibliográfico onde expôs resultados atribuídos a meio qualitativos e quantitativos referente ao material já existente.

Segundo a Organização das Nações Unidas - ONU, o ranking do Índice de Desenvolvimento Humano é dividido em quatro categorias:

(Físico-motor, intelectual, efetivo-emocional e social).

- Físico-motor: refere-se ao crescimento orgânico e a maturação neurofisiológica.

- Intelectual: é a pessoa que produz pensamentos.

- Efetivo-emocional: é como o indivíduo associa as suas experiências.

- Social: a relação com a sociedade.

Cada uma delas considera os aspectos relacionados ao desenvolvimento das nações, geração,distribuição de renda, programas de atenção básica e qualidade de vida.

Entenda essas divisões e alguns países que fazem parte de cada uma delas:

\section{Muito alto}

Noruega: 0,953

Suíça: 0,944 
Austrália: o,939

Irlanda: 0,938

Alemanha: 0,93

2. Alto

Irã: 0,798

Palau: 0,798

México: o,744

Venezuela: o,76B

Brasil: 0,759

\section{Médio}

Filipinas: 0,699

Egito: o,696

Bolívia: o,693

Índia: o,640

4. Baixo

Uganda: 0,516

Haiti: o,498

Congo: 0,457

Níger: o,354

Serra Leoa: 0,413 


\section{CONSIDERAÇÕES FINAIS}

Levando em consideração os dados coletados pode-se perceber que os países de primeiro mundo possuem uma taxa de desenvolvimento econômico mais elevada, onde fica explicito que os paísesque tem sua capital voltada para as indústrias e os setores terciário predominam a economia maiselevada dos países.

Nota-se também que aqueles países onde os indivíduos procura buscar o aprendizado, com pesquisas científicas, são os mais que conseguem se sobressair e transformar o meio que habita, por que são os que buscam modernizar os equipamentos "eletrônicos" para melhor ajudar sua população.

Por fim, entende-se que para um país se tornar desenvolvido precisa-se pelo menos possuir ascaracterísticas a seguir:

- Elevar rendimento per capita da população;

- Taxas de crescimento altas;

- Ofertar empregos nos setores da indústria;

- Elevar o nível da cultura;

- Nível muito baixo de mortalidade;

Assim finalizo com a esperança de um país com direitos e igualdade para todos, onde os menosfavorecidos consigam ter uma melhor qualidade de vida

\section{REFERÊNCIAS BIBLIOGRÁFICAS}

NEVES, J. Países Desenvolvidos. Disponível em ::〈https://www.educamaisbrasil.com.br> Acesso: 09/06/2021.

Mundo Educação. Disponível em:<https://mundoeducacao.uol.com.br/vidos.htm $>$ Acesso o. h:37min 
RIBEIRO, C. Países Desenvolvidos. Disponível em 09/o6/2021:https://www.infoescola.com/ geografia/paises-desenvolvidos>Acesso: $07 \mathrm{~h}: 45 \mathrm{~min}$

Mundo Educação. Disponível em:https://mundoeducacao.uol.com.br/ lizacao-norte-sul.htm> Acesso: 09/06/2021:

IANNI, O. A Questão Nacional $\mathrm{Na}$ América Latina. Disponível em:<https://www.scielo.br/j/ea/a/RCPQ59yCw3tP?lang=pt $>$ Acesso: 09/o6/2021

MACHADO, L. T. A Teoria Da Dependência $\mathrm{Na}$ América Latina. https://www.scielo.br/j/ea/a/mjsc7pDvgc. Acesso: 09/o6/2021: 